\title{
Optimization of Game Formats in U-10 Soccer Using Logistic Regression Analysis
}

\author{
by \\ Mario Amatria1, Daniel Lapresa², Javier Arana³, M. Teresa Anguera4, Belén Garzón²
}

Small-sided games provide young soccer players with better opportunities to develop their skills and progress as individual and team players. There is, however, little evidence on the effectiveness of different game formats in different age groups, and furthermore, these formats can vary between and even within countries. The Royal Spanish Soccer Association replaced the traditional grassroots 7-a-side format (F-7) with the 8-a-side format (F-8) in the 201112 season and the country's regional federations gradually followed suit. The aim of this observational methodology study was to investigate which of these formats best suited the learning needs of U-10 players transitioning from 5-aside futsal. We built a multiple logistic regression model to predict the success of offensive moves depending on the game format and the area of the pitch in which the move was initiated. Success was defined as a shot at the goal. We also built two simple logistic regression models to evaluate how the game format influenced the acquisition of technicaltactical skills. It was found that the probability of a shot at the goal was higher in F-7 than in F-8 for moves initiated in the Creation Sector-Own Half (0.08 vs 0.07) and the Creation Sector-Opponent's Half (0.18 vs 0.16). The probability was the same (0.04) in the Safety Sector. Children also had more opportunities to control the ball and pass or take a shot in the F-7 format (0.24 vs 0.20), and these were also more likely to be successful in this format (0.28 vs 0.19).

Key words: soccer, adaptation, child, observational methodology, logistic regression.

\section{Introduction}

The potential benefits of sport for children extend beyond the mere practice of sport (Holt et al., 2006). Children who take part in learningbased sports activities, i.e. activities tailored to their learning needs, will develop better motor, situational, psychological and social skills than children who take part in activities largely focused on results (Holt et al., 2012). In addition, results-based sporting activities may even have a detrimental outcome on the overall learning process (Malina, 2001). In soccer, the relationship between the number of players and the size of the pitch influences a child's ability to perform technical-tactical tasks effectively and efficiently, and can also affect their sensation of competence (Clemente et al., 2012).

There is broad consensus across soccer federations in Europe and indeed worldwide that young soccer players should play small-sided games, as these allow for better skill development and understanding of individual and group tactics. There is, however, variation between countries and even within countries, as the bodies responsible for organizing regional youth leagues are frequently free to decide which competition format to use. This is the case in Spain, for example, which has 19 regional federations. A wide range of game formats are used across the

\footnotetext{
1 - Department of Physical Activity Sciences and Sports. Pontifical University of Salamanca, Spain.

2 - Department of Educational Sciences. University of La Rioja, Spain.

3 - Department of Education. International University of La Rioja (UNIR), Spain.

4 - Department of Behavioural Sciences Methodology, Institute of Brain, Cognition and Behavior. University of Barcelona, Spain.
} 
country up to the junior level (12-14 category), which is when the standard 11-a-side format (F11) is introduced. At the III Grassroots Soccer Conference organised by the Royal Spanish Soccer Association (RFEF) in 2005, representatives of the association discussed the possibility of replacing the format used at the time for U-12 players, i.e. 7a-side soccer (F-7), with 8-a-side soccer (F-8), which was considered to be more balanced. The F-8 format was introduced for all youth soccer matches played between teams representing Spain's 19 regions in the 2011-2012 season, and logically, the different federations throughout Spain followed suit by gradually introducing this format for regional leagues. As mentioned, the situation across Europe varies considerably, with different small-sized game formats used for different age groups. It is therefore important to analyze specific formats in specific age groups to determine their impact on learning. In the current study, within the framework of an observational methodology design (Anguera, 1979), we applied a series of logistic regression models to investigate whether F-7 or F-8 was better suited to the learning needs of children aged 8-10 years moving up from futsal (F-5). The matches analyzed took place at the end of the 2011-2012 season between teams about to move up from F-5 to the newly introduced F-8 format.

Considering the multiple dichotomous variables of interest in studies of sport, together with the potential offered by logistic regression analysis applied to observational methodology (Lapresa et al., 2016), recent years have witnessed a marked increase in the number of observational methodology studies applying logistic regression analysis to the field of sport and physical activity (Tenga et al., 2010; Arana et al., 2013; Casal et al., 2015). We built a multiple logistic regression model to predict the success of offensive moves by players aged 8-10 years in three game formats (F-5, F-7 and F-8) according to the zone of the pitch in which the move was initiated. Success was defined as a shot at the goal (Castellano et al., 2012; Lapresa et al., 2013a). In addition, we built two simple logistic regression models to analyze the technical-tactical performance of players according to how well each of the game formats met their learning needs (Yates and Williams, 2009; Stratton et al., 2004) and influenced the chances of a successful outcome (Lames and
McGarry, 2007).

Although many clubs and federations now use the F-8 rather than the F-7 format, there is no clear evidence on which format offers the most favorable learning environment for young soccer players. In this study, we performed an exploratory study to examine whether the recently introduced F-8 format provided better learning and skills development opportunities among U-10 soccer players who had just moved up from F-5.

\section{Material and Methods}

The observational design employed was nomothetic (observation of three first-year U-10 soccer teams), multidimensional (focus on numerous dimensions that comprised the observation instrument used), and consisted of inter-sessional and intra-sessional follow-up (i.e. analysis of successive matches for each of the three game formats studied) (Anguera et al., 2011). Observation was non-participatory, active, scientific and characterized by total perceptivity.

\section{Participants}

We used an intentional sample drawn from an F-5 competition organised by one of Spain's regional federations for players in their first year of the U-10 category. Participation in this competition was determined by the number of matches the teams had won in the regional league (F-5). The three top-ranking teams in the tournament were then invited to play in an F-5, F7 and F-8 triangular tournament. To ensure intersessional consistency, the following parameters were kept constant across all matches: a pitch (a university sports hall for the F-5 tournament and a standard artificial grass pitch for the F-7 and F-8 tournaments), match length (50 minutes for F-5 and 30 minutes for F-7 and F-8), a referee (the same for all matches), ball size (no. 5 for F-5 and no. 4 for F-7 and F-8), and division of the pitch into equivalent zones using rubber adhesive tape and cones placed just outside the perimeter of the pitch.

\section{Observation instrument}

We used the observation instrument designed to study technical-tactical actions in grassroots soccer. The instrument is based on different versions of the Football Observation System (SOF, after its initials in Spanish) (Jonsson et al., 2006). It is a combined field-format category 
system, with exhaustive, mutually exclusive categories nested in a multidimensional field format structure (Anguera and HernándezMendo, 2013). The pitch (40 x $20 \mathrm{~m}$ for F-5 and 70 x $40 \mathrm{~m}$ for F-7 and F-8) was divided into three equally sized horizontal sections and three equally sized channels running the length of the pitch. The three horizontal sections were defined as the Safety Sector (defending third), the Creation Sector (midfield third), and the Definition Sector (attacking third). The creation sector was further divided into two subsections comprising zones 40,50 and 60 on one side of the half-way line (Own Half) and zones 41, 51, 61 on the other side (Opponent's Half) (Table 1).

\section{Procedure}

The data were recorded and coded in the multiplatform software application LINCE (v. 1.2.1) (Gabín et al., 2012). Each match was broken down into moves (or sequences of play), which in turn, were broken down into actions (types of contact with the ball). The final sample consisted of 541 moves for F-5, 324 moves for F-7, and 346 moves for F-8. The respective number of actions was 1388, 947 and 953.

\section{Data quality control: agreement between observations and generalizability of results}

The reliability of the data used for the analysis was ensured using a consultative agreement method involving two observers. One of the observers coded the data twice. The first time, he coded all the data corresponding to the team being observed in each of the matches (full sample), and the second time, he recoded at least $10 \%$ of the actions comprising each of the resulting data sets. A second observer then searched for discrepancies between matching pairs of data sets and made a final decision on which option to include in the definitive data set. This consultative procedure allows for the detection, analysis and characterization of discrepancies. All the discrepancies detected were related to differences in the identification of moves ( $\geq 2$ successive contacts with the ball versus occasional interception with continuation of play, i.e. only 1 contact); this lack of agreement resulted in incorrect alignment of observations (Quera et al., 2007). Thus, we applied the consultative agreement method to overcome the limitations of within-observer agreement in cases where it was not possible to use a second observer to code all of the data. Agreement between data was analyzed using Cohen's kappa statistic in GSEQ (v.5) following the recommendations of Bakeman and Quera (2011). Each of the data sets (team observed/match) produced for the three game formats yielded a kappa statistic of over 0.86, which according to the criteria of Prieto et al. (2014) guaranteed the agreement between them.

Within the generalizability theory (Cronbach et al., 1972), we used the design Category / Match (C/M) for the three game formats. The relative generalizability coefficients for each of the game formats $\left(\mathrm{e}^{2}=0.94\right.$ for $\mathrm{F}-5$; $\mathrm{e}^{2}=$ 0.97 for F-7; and $\mathrm{e}^{2}=0.95$ for F-8) indicated a high degree of generalizability, demonstrating the interpretative reliability of the data recorded across the different matchs in each game format.

\section{Data analysis}

A multiple logistic regression model was built to analyze the probability of a move being successful according to the Game Format and Move Initiation Zone. The criterion variable was thus dichotomised into success (move resulting in a shot at the goal) or failure (move not resulting in a shot at the goal). The two predictor variables were the Move Initiation Zone (Safety Sector, Creation Sector in Own Half, Creation Sector in Opponent's Half and Definition Sector) and Game Format (F-5, F-7 and F-8). As both of these predictors were categorical variables with more than two categories, we generated dichotomous dummy variables, while maintaining the information provided by the original variable. The reference categories used were the Definition Sector for the Move Initiation Zone and F-5 for the Game Format. The multiple logistic regression model employed is shown below, where $P(Y)$ is the probability of an event occurring; $e$, Euler's constant $=2.718281 ; X i(i=1,2, \ldots, k)$, the predictor variables; $\beta o$, the constant; and $\beta i(i=1,2, \ldots, k)$, the logistic regression coefficients:

$$
P(Y)=\frac{1}{1+e^{-\left(\beta_{0}+\beta_{1} X_{1}+\beta_{2} X_{2}+\ldots+\beta_{k} X_{k}\right)}}
$$

Two simple logistic regression models were built to analyze the technical-tactical performance of U-10 players in F-5, F-7 and F-8. The first criterion variable referred to whether or not the format was adapted to the children's learning needs. The two categories within this criterion were thus Adapted (observation of C2, i.e. control of the ball followed by a pass or a shot 
at the goal) and Not Adapted (C2 not observed). In the second model, the criterion variable, which was also related to the learning needs of the children, was also divided into Adapted and Not Adapted, but with the distinction that the pass made following control of the ball was successful, i.e. it resulted in continuation of play by a team member. Since these two models were simple regression models, they included a single predictor (Game Format, for which the reference variable was F-5). The model included thus just one coefficient: $(\beta \mathrm{o}+\beta X)$.

\section{Results}

\section{Multiple logistic regression model}

Considering that the criterion variable Success (move resulting in a shot at the goal) was significantly associated with the predictors Move Initiation Zone $\left(\chi^{2}=64.47 ; p=0.50\right)$ and Game Format $\left(\chi^{2}=10.23 ; p \leq 0.001\right)$, these two predictors were included in the multiple logistic regression model. Colinearity was ruled out as the association between the predictors was not statistically significant $\left(\chi^{2}=2.81 ; p=0.83\right)$. We next analyzed the possibility of confounding and interaction. In the confounding analysis, the $\operatorname{Exp}(B)$ values corresponding to the Move Initiation Zone displayed a variation of less than $10 \%$ when the Game Format was added to the model, meaning therefore that the three dummy categories for the Move Initiation Zone were maintained in the model. Interaction was also ruled out, as the Game Format coefficient was not significant when interaction between variables was introduced into the model. Three SPSS procedures, i.e. Enter, Forward Selection and Backward Elimination, were used to select the variables to include in the predictive regression model and to estimate the strength of the association between the criterion and the predictor variables. Each of the procedures indicated that the Safety Sector, Creation Sector in Own Half, Creation Sector in the Opponent's Half, F-7 and F-8 should be included in the model.

In our analysis of the discrimination power of the model, we found that it accurately predicted $85.63 \%$ of all moves analyzed, with sensitivity of $0 \%$ (ability to correctly predict a successful move) and specificity of 100\% (ability to correctly predict an unsuccessful move). Application of the Hosmer-Lemeshow goodness- of-fit test showed the absence of significant differences between the expected and observed values $\left(\chi^{2}=1.55 ; p=0.99\right)$, confirming that the model fitted the data.

The resulting logistic regression model was then used for estimation and prediction purposes. The $\operatorname{Exp}(\mathrm{B})$ value for F-7 was $0.611(>1$ and therefore significant), indicating that the probability of a move ending in a shot was $38.9 \%$ lower in F-7 than in F-5 (Table 2). The corresponding value for $\mathrm{F}-8$ was 0.528 , again indicating that there was a $47.2 \%$ lesser chance of a move ending in a shot at the goal in F-8 than in F-5. For the second predictor, the Move Initiation Zone, the $\operatorname{Exp}(\mathrm{B})$ value for the Safety Sector was 0.166 , indicating that there was an $83.4 \%$ lower probability of a move ending in a shot when it was initiated in this part of the pitch as compared with the Definition Sector. The $\operatorname{Exp}(\mathrm{B})$ for the Creation Sector in Own Half was 0.298 and therefore, the probability of success in this sector was $70.2 \%$ less than in the Definition Sector. Finally, the $\operatorname{Exp}(B)$ value for the Creation Sector in the Opponent's Half was not significant, showing that there was no difference between this part of the pitch and the Definition Sector in terms of the chances of a move ending in a shot at the goal.

For the prediction analysis, the probability of success (shot at the goal) in F-7 was 0.04 for moves initiated in the Safety Sector and 0.08 and 0.18 for those initiated in the attacking team's Creation Sector and the opposing team's Creation Sector, respectively. The respective figures for F-8 were 0.04, 0.07 and 0.16.

Simple logistic regression analyses

We observed a significant association between each of the criterion variables (Adapted: Control + Pass or Shot; and Control + Successful Pass or Shot $)$ and the Game Format $\left(\chi^{2}=8.43 ; p=\right.$ $0.01)$. The game format was thus incorporated as the predictor variable in the two simple logistic regression models, which were developed using the ENTER procedure in SPSS.

The first model accurately predicted $78.36 \%$ of all moves analyzed, with sensitivity of $0 \%$ and specificity of $100 \%$. The HosmerLemeshow goodness-of-fit test showed an absence of significant differences between the expected and observed values $\left(\chi^{2} \leq 0.001 ; p=1\right)$. The $\operatorname{Exp}(\mathrm{B})$ value for F-7 was 1.29 ( $>1$ and thus significant), indicating that the probability of ball control + 
pass or shot was 1.29 times higher than in F-5 (Table 3). The $\operatorname{Exp}(\mathrm{B})$ value for F-8 was not significant, meaning that there was no significant difference between this format and F-5 in terms of adaptation to the learning needs of the players (C2). In the prediction analysis, the probability of contact with the ball adapted to the needs of the players was 0.24 in F-7 and 0.20 in F-8.

\begin{tabular}{|c|c|c|c|c|c|c|}
\hline \multicolumn{7}{|c|}{ Table 1} \\
\hline \multicolumn{7}{|c|}{ Observation Instrument } \\
\hline No. & Criterion & \multicolumn{5}{|l|}{ Category Codes \& Brief Description } \\
\hline 1 & $\begin{array}{c}\text { Ball } \\
\text { possession }\end{array}$ & \multicolumn{5}{|c|}{$\begin{array}{l}\text { PO) Possession of ball by team being observed; PC) Possession of ball by opposing team; Unob) } \\
\text { Unobservable. }\end{array}$} \\
\hline 2 & $\begin{array}{c}\text { Move } \\
\text { initiation } \\
\text { zone } \\
\end{array}$ & $\begin{array}{l}\text { ZS10, ZS20, ZS30-safety sector; ZS40, ZS50, ZS60-creation sector; } \\
\text { ZS70, ZS80, ZS90-definition sector. }\end{array}$ & 10 & 40 & 41 & 70 \\
\hline \multirow[t]{2}{*}{3} & \multirow[b]{2}{*}{$\begin{array}{c}\text { Move } \\
\text { conclusion } \\
\text { zone }\end{array}$} & \multirow[b]{2}{*}{$\begin{array}{l}\text { ZE10, ZE20, ZE30-safety sector; ZE40, ZE50, ZE60-creation section; } \\
\text { ZE70, ZE80, ZE90-definition sector. }\end{array}$} & 20 & 50 & 51 & 80 \\
\hline & & & 30 & 60 & 61 & 90 \\
\hline 4 & $\begin{array}{l}\text { Contact } \\
\text { with ball }\end{array}$ & \multicolumn{5}{|c|}{$\begin{array}{l}\text { C1) single touch and regulatory throw-in/kick-in; C12) attempt to control the ball with } 2 \text { or more } \\
\text { touches resulting in loss of the ball; C2) control of the ball (including picking up of the ball by } \\
\text { goalkeeper) followed by a pass or shot -regardless of whether the ball reaches a team member or is } \\
\text { recovered by an opponent; C23) control of the ball, followed by dribbling and loss of the ball; C24) } \\
\text { control of the ball, followed by dribbling, attempt to go around one or more opponents, and loss of } \\
\text { the ball; C3) control of the ball, followed by dribbling and a pass or a shot -regardless of whether the } \\
\text { ball reaches a team member or is recovered by an opponent; C4) control of the ball, passing of one or } \\
\text { more opponents, and a pass or a shot -regardless of whether the ball reaches a team member or is } \\
\text { recovered by an opponent; C5) Header. }\end{array}$} \\
\hline 5 & $\begin{array}{l}\text { Interrup- } \\
\text { tions }\end{array}$ & \multicolumn{5}{|c|}{$\begin{array}{l}\text { FDFT) free kick for the team being observed; FDFJ) offside for the team being observed; FFSB) throw- } \\
\text { in for the team being observed; FFSE) corner kick for the team being observed; FFSP) goal kick for } \\
\text { the team being observed; CDFT) free kick against the team being observed; CDFJ) offside against the } \\
\text { team being observed; CFFB) throw-in against the team being observed; CFFF) corner kick or goal } \\
\text { kick against the team being observed; GF) goal scored by the team being observed; GC) goal } \\
\text { conceded by the team being observed; SN) neutral kick. }\end{array}$} \\
\hline 6 & $\begin{array}{c}\text { Intercep- } \\
\text { tions }\end{array}$ & \multicolumn{5}{|c|}{ P) loss of the ball; R) recovery of the ball; IOC) occasional interception with continuation of play. } \\
\hline 7 & Shot & \multicolumn{5}{|c|}{$\begin{array}{l}\text { TG) shot resulting in a goal; TI) shot intercepted by an opponent other than the goalkeeper; TM) shot } \\
\text { between the posts not resulting in a goal; TF) shot wide of the posts; TP) shot saved or cleared by the } \\
\text { goalkeeper. }\end{array}$} \\
\hline
\end{tabular}

\begin{tabular}{|c|c|c|c|c|c|c|}
\hline \multicolumn{7}{|c|}{$\begin{array}{l}\text { Estimated results for model coefficients: } B, \operatorname{Exp}(B), \text { confidence intervals and levels of } \\
\text { significance in the multiple logistic regression model }\end{array}$} \\
\hline & B & S.E. & Wald & df & $p$ & $\operatorname{Exp}(B)$ \\
\hline Format & & & 11.388 & 2 & 0.003 & \\
\hline F-7 & -0.492 & 0.21 & 5.495 & 1 & 0.019 & 0.611 \\
\hline $\mathrm{F}-8$ & -0.639 & 0.211 & 9.178 & 1 & 0.002 & 0.528 \\
\hline Move initiation zone & & & 58.677 & 3 & 0 & \\
\hline Safety zone & -1.794 & 0.276 & 42.258 & 1 & 0 & 0.166 \\
\hline Creation zone own half & -1.211 & 0.242 & 24.998 & 1 & 0 & 0.298 \\
\hline Creation zone opponent's half & -0.292 & 0.218 & 1.797 & 1 & 0.18 & 0.747 \\
\hline Constant & -0.691 & 0.183 & 14.195 & 1 & 0 & 0.501 \\
\hline
\end{tabular}


Table 3

Estimated results for model coefficients: $B, \operatorname{Exp}(B)$, confidence intervals and levels of significance in the simple logistic regression models

\begin{tabular}{|c|c|c|c|c|c|c|}
\hline First simple logistic regression model & B & S.E. & Wald & df & $p$ & $\operatorname{Exp}(B)$ \\
\hline Format & & & 8.41 & 2 & 0.015 & \\
\hline F-7 & 0.261 & 0.1 & 6.764 & 1 & 0.009 & 1.298 \\
\hline F-8 & -0.007 & 0.105 & 0.004 & 1 & 0.949 & 0.993 \\
\hline Constant & -1.364 & 0.067 & 419.299 & 1 & 0 & 0.256 \\
\hline Second simple logistic regression model & B & S.E. & Wald & df & $p$ & $\operatorname{Exp}(B)$ \\
\hline Format & & & 11.757 & 2 & 0.003 & \\
\hline F-7 & 0.311 & 0.129 & 5.795 & 1 & 0.016 & 1.365 \\
\hline F-8 & -0.176 & 0.142 & 1.532 & 1 & 0.216 & 0.839 \\
\hline Constant & -1.226 & 0.087 & 199.809 & 1 & 0 & 0.294 \\
\hline
\end{tabular}

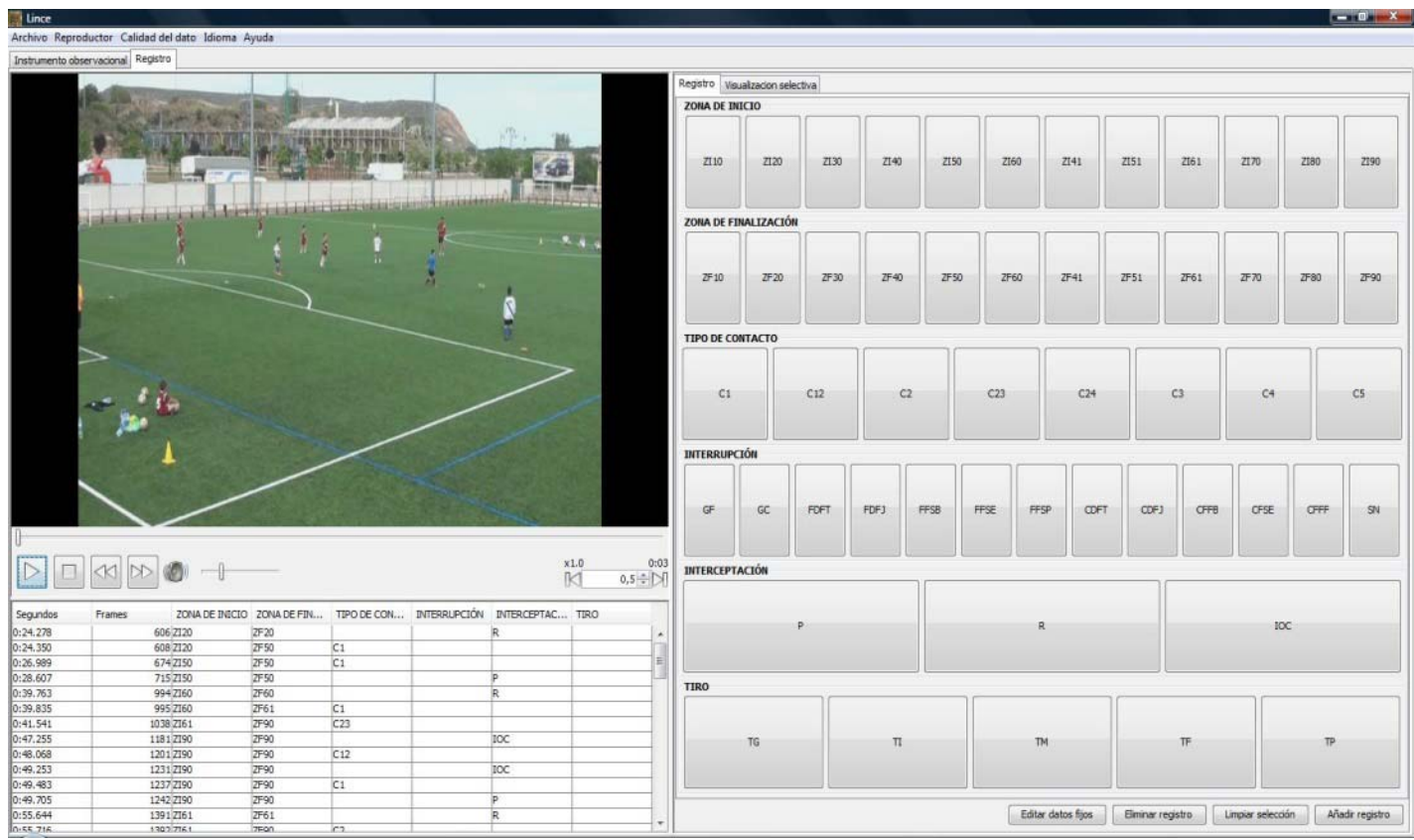

Figure 1

Screenshot of a recording/coding screen in Lince (v. 1.2.1). 
The second simple logistic regression model accurately predicted $76.37 \%$ of all moves analyzed, with sensitivity of $0 \%$ and specificity of $100 \%$. The goodness of fit as analyzed by the Hosmer-Lemeshow test was also adequate $\left(\chi^{2} \leq\right.$ $0.001 ; p=1)$. The $\operatorname{Exp}(\mathrm{B})$ value for F-7 was significant at 1.36 , meaning that the probability of ball control + successful pass or shot was 1.36 times higher in F-7 than in F-5 (Table 3). The same analysis for F-8 showed a lack of significance $(\operatorname{Exp}(\mathrm{B})$ of 0.83$)$ indicating that the creation of ball contact situations tailored to the learning needs of the children did not vary significantly between F8 and F-5. Finally, the probability of a move resulting in ball control + successful pass or shot was 0.28 for F-7 and 0.19 for F-8.

\section{Discussion}

Our study provides insights into which small-sized game format (F-7 or F-8) might provide better learning opportunites for secondyear U-10 soccer players transitioning from the F5 format, which in addition to involving fewer players is played on a smaller pitch. Our results indicate that the recently substituted F-7 format is a better option in this setting.

In addition, we showed the potential of logistic regression analysis applied to soccer within the field of observational methodology. This is particularly relevant considering the multiple number of dichotomous situations (e.g. success vs failure, efficient vs not efficient, adapted vs not adapted, appropriate vs not appropriate, etc.) that arise in studies of sport and physical activity (Lapresa et al., 2016). We built a multiple logistic regression model to analyze the technical/tactical use of space by U-10 soccer players to create goal-scoring opportunities in three game formats (F-5, F-7 and F-8) and two simple logistic regression models to investigate how appropriate each of these formats was for helping children to acquire technical-tactical skills.

The multiple logistic regression model allowed us to investigate the probability of a move being successful or not (goal-scoring opportunity) (Castellano et al., 2012; Lapresa et al., 2013a) according to the zone of the pitch in which it was initiated and the format of the game. Our results show that, regardless of format, the chances of a shot at the goal resulting from a move decreased with distance from the opponent's goal. This observation is consistent with previous observations by Lapresa et al. (2016) for grassroots soccer. Furthermore, the probability of a move resulting in a shot at the goal was higher in F-7 than in F-8, regardless of where the move began. This confirms the better quality of play, i.e. greater probability of a move ending in a shot at the goal depending on the zone of the pitch in which the move was initiated, demonstrated for F-7 compared with F-8.

In the first simple logistic regression model, in which we investigated the suitability of the different game formats for the development of young players' technical-tactical skills, our criterion variable was category $\mathrm{C} 2$ from the observation instrument (control of ball + pass or shot). Control of the ball followed by a pass or a shot at the goal was used to denote success because a) it is particularly relevant in the sequential acquisition of technical-tactical skills as it facilitates the transition from individual play (dribbling) to team play (control and passing) (Stratton et al., 2004) and b) combination play is a key element of play in F-7 and F-8, as players need to use passes to exploit the space (Castelão et al., 2014; Castellano and Etxeazarra, 2014). C2 was also the only type of contact for which significant differences were noted between F-5, F-7 and F-8. This first model showed that the probability of this type of contact with the ball was higher in F-7 than in F-8. The second simple logistic regression model showed similar results for the other criterion variable, which looked at ball control + successful pass (Jones et al., 2004; Scoulding et al., 2004) and/or shot (Tenga et al., 2010; Sarmento et al., 2015). The results of both simple logistic regression models are consistent with previous findings for studies comparing F-7, F-9 and F-11 in children aged 11-12 (Lapresa et al., 2006), and for studies comparing F-7 and F-11 in children aged 11-12 (Capranica et al., 2001).

Although convenience samples can be considered a limitation due to concerns about their representativeness, in our case, the analysis of just three teams and nine matches was offset by a high degree of generalizability of the results obtained, as this shows that our sample was homogeneous and as such adequate for the purpose of the study (Arana et al., 2013).

In conclusion, the results of the present 
study indicate that F-7 is a more suitable format than F-8 for 8-to-10-year-olds moving up from F5 , as it is more conducive to the development of technical and tactical skills at this age (Stratton et al., 2004; Yates and Williams, 2009; Lapresa et al., $2013 b)$. Considering the variability in small-sized game formats across different age groups and leagues, more studies are needed to evaluate the effectiveness of these formats to ensure that they provide both coaches and players with optimal skills development opportunities.

\section{Acknowledgements}

We gratefully acknowledge the support of both Spanish government projects: La actividad física y el deporte como potenciadores del estilo de vida saludable: Evaluación del comportamiento deportivo desde metodologías no intrusivas (Secretaría de Estado de Investigación, Desarrollo e Innovación del Ministerio de Economía y Competitividad) during the period 2016-2018 [Grant DEP2015-66069-P (MINECO/FEDER, UE)], and Avances metodológicos y tecnológicos en el estudio observacional del comportamiento deportivo (Secretaría de Estado de Investigación, Desarrollo e Innovación del Ministerio de Economía y Competitividad) during the period 2015-2017 [Grant PSI2015-71947-REDT]. This study was funded by grants from the University of La Rioja.

\section{References}

Anguera MT. Observational Typology. Qual Quant, 1979; 13(6): 449-484

Anguera MT, Blanco-Villaseñor A, Hernández-Mendo A, Losada JL. Observational designs: their suitability and application in sport psychology. Cuadernos Psicol Deporte, 2011; 11(2): 63-76.

Anguera MT, Hernández-Mendo A. Observational methodology in sport sciences. E-balonmano.com: J Sport Sci, 2013; 9(3): 135-160

Arana J, Lapresa D, Anguera MT, Garzón B. Adapting football to the child: an application of the logistic regression model in observational methodology. Qual Quant, 2013; 47(6): 3473-3480.

Bakeman R, Quera V. Sequential analysis and observational methods for the behavioral sciences. Cambridge: University Press; 2011

Capranica L, Tessitore A, Guidetti L, Figura F. Heart rate and match analysis in pre-pubescent soccer players. J Sport Sci, 2001; 19(6): 379-384

Casal C, Maneiro R, Ardá T, Losada JL, Rial A. Analysis of corner success in elite football. Int J Perform Anal Sport, 2015; 15(2): 430-451

Castelão D, Garganta J, Santos R, Teoldo I. Comparison of tactical behaviour and performance of youth soccer players in 3v3 and 5v5 small-sided games. Int J Perform Anal Sport, 2014; 14(3): 801-813

Castellano J, Casamichana D, Lago C. The use of match statistics that discriminate between successful and unsuccessful soccer teams. J Hum Kinet, 2012; 31: 137-147

Castellano J, Etxeazarra I. Adapting the competition model in youth football: a comparison between 5-a-side and 7-a-side football with U10-players. In Science and football VII. Eds. Nunome H, Drust B, Dawson, B. London: Routledge, 311-316; 2014

Clemente F, Couceiro MS, Martins FM, Mendes RU. The usefulness of small-sided games on soccer training. J Phys Educ Sport, 2012; 12(1): 93-102

Cronbach LJ, Gleser GC, Nanda H, Rajaratnam N. The dependability of behavioral measurements: theory of generalizability for scores and profiles. New York: Wiley; 1972

Gabín B, Camerino O, Anguera MT, Castañer M. Lince: multiplatform sport analysis software. Procedia Soc Behav Sci, 2012; 46: 4692-4694

Holt JE, Kinchin G, Clarke G. Effects of peer-assessed feedback, goal setting and a group contingency on performance and learning by 10-12-year-old academy soccer players. Phys Educ Sport Ped, 2012; 17(3): $231-250$ 
Holt JE, Ward P, Wallhead TL. The transfer of learning from play practices to game play in young adult soccer players. Phys Educ Sport Ped, 2006; 11(2): 101-118

Jones PD, James N, Mellalieu SD. Possession as a performance indicator in soccer. Int J Perform Anal Sport, 2004; 4(1): 98-102

Jonsson GK, Anguera MT, Blanco-Villaseñor A, Losada J, Hernández-Mendo A, Ardá T, Camerino O, Castellano J. Hidden patterns of play interaction in soccer using SOF-CODER. Beh Res Meth Ins C, 2006; 38(3): 372-381

Lames M, McGarry T. On the search for reliable performance indicators in game sports. Int J Perform Anal Sport, 2007; 7(1): 62-79

Lapresa D, Álvarez L, Arana J, Garzón B, Caballero V. Observational analysis of the offensive sequences that ended in a shot by the winning team of the 2010 UEFA Futsal Championship. J Sport Sci, 2013; 31(15): 1731-1739 (a)

Lapresa D, Arana J, Anguera MT, Garzón B. Comparative analysis of the sequentiality using SDIS-GSEQ and THEME: a concrete example in soccer. J Sport Sci, 2013; 31(15): 1687-1695 (b)

Lapresa D, Arana J, Anguera MT, Pérez JI, Amatria M. Application of logistic regression models in observational methodology: game formats in grassroots football in initiation into football. An Psicol, 2016; 32(1): 288-294

Lapresa D, Arana J, Garzón B. 9 football as an adjustment alternative to 11 football, based on the control of the space. Rev Apunts Educ Fís Deportes, 2006; 86: 34-44

Malina R. Youth football players: perspectives from growth and maturation. Insight, The F. A. Coaches Assoc J, 2001; 1(5): 27-31

Prieto I, Gutiérrez-Santiago A, Lage MAP. Knowledge of Errors in the Teaching-Learning Process of JudoTechniques: Osoto-Guruma as a Case Study. J Hum Kinet, 2014; 41: 253-263

Quera V, Bakeman R, Gnisci A. Observer agreement for event sequences: Methods and software for sequence alignment and reliability estimates. Beh Res Meth, 2007; 39(1): 39-49

Sarmento H, Bradley P, Anguera MT, Polido T, Resende R, Campaniço J. Quantifying the offensive sequences that result in goals in elite futsal matches. J Sport Sci, 2016; 34(7): 621-629

Scoulding A, James N, Taylor J. Passing in the soccer World Cup 2002. Int J Perform Anal Sport, 2004; 4(2): 3641

Stratton G, Reilly T, Williams AM, Richardson D. Youth soccer: from science to performance. London: Routledge; 2004

Tenga A, Ronglan L, Bahr R. Measuring the effectiveness of offensive match-play in professional soccer. Eur J Sport Sci, 2010; 10(4): 269-277

Yates IS, Williams AM. The microstructure of effective practice: the nature of the instruction process in soccer. In Science and football VI. Eds. Reilly T, Korkusuz F. London: Routledge, 438-441; 2009

\section{Corresponding author:}

\section{Daniel Lapresa, PhD}

Department of Educational Sciences / University of La Rioja.

Edificio Vives. C/ Luis de Ulloa s/n.

26004. Logroño. La Rioja - Spain

Phone: +34 941299282

E-Mail: daniel.lapresa@unirioja.es 